\title{
Rethinking the Impact of Urban Form in Sustainable Urban Planning Policy
}

\author{
Séverine Hermand ${ }^{1}$ and Monica García Quesada ${ }^{2}$
}

\begin{abstract}
This paper examines how urban form affects the sustainable development of cities. It look at the case of Brussels, a city and a region with a very distinctive position in Belgium and in Europe, where public and political institutions have developed together detailed management plans to ensure the responsible management of the city in environment, social and economic terms. The paper first examines the concept of urban form and its constituent features. It then analyses two main questions: How can urban form indicators be integrated in decision-making process for sustainable urban planning? What urban development priorities are in place in Brussels-Capital Region and how do they impact the urban form development of the city? By proposing an analysis on the notion of urban form in Brussels-Capital Region, this paper intends to equip designers and decision makers with a better overview the type of city environmental strategies that can be deployed in the early stages of urban development projects.
\end{abstract}

Keywords: Urban form, Density, Polycentric, Brussels-Capital Region, Policy development

\section{Introduction}

The analysis of urban form is an important design tool to examine the formation and the development of cities' physical environment over time. Cities' diversity and complexity is somehow reflected in the variety of approaches to describe and explain their physical form. These approaches provide different answers to questions such as, what is the form of a city? From which point of view do we analyze it? What are the various kinds of forms that we are talking about? How does the study of urban form can be used in urban planning? Depending on the answers to these questions, urban planning will have different and definitive features.

Environmental, social and economic constraints have forced public representatives, architects and planners to rethink urban planning. The adaptation to local climate conditions and the need to envisage buildings that respect and enhance the environment have become primary concerns for urban designers, which are in turn strongly influencing the shape of cities. The different approaches to urban practices have gained in further complexity, and so a great array of different approaches exist -smart growth, sustainable cities, eco-cities, liveable-cities, green and low-carbon cities.

This research is an attempt to bridge the different urban form analyses. We argue that, particularly due to the development of the sustainable urban design, there is a need for one methodology that takes account of the new context of complex urban form

${ }^{1} \mathrm{PhD}$ candidate and teaching assistant at the BATir service, AIA (Architecture and Architectural engineering) department of the Brussels School of Engineering, and the Free University of Brussels (ULB) since 2012.

${ }^{2}$ Visiting Researcher at at BATir - Building, Architecture and Town Planning, at Université Libre de Bruxelles (ULB) in Belgium. 
system and also of the multiplicity of methods to analyze the urban system. The difficulty of this endeavor lies in simplifying urban complexity in such a way that it can be easily grasped by the mind, while avoiding reductive schemes, which disregard the specificity of the issue. For this, this article takes the concept of urban form both as a descriptive term, in that it refers to the shape of a city, and as an instrument for planning, as it makes us consider how urban form affects the different functionalities and their impact on the city. In doing so, the article does not provide an exhaustive account of the definition and method of analysis of urban form, but examines its main features to think about, investigate and work with urban built environment.

Thus, we seek to contribute to the development of a methodology to examine urban form in the current context of sustainable development. The study could also be used as a policy tool to set up guidelines and support a more integrated sustainable approach to urban regulation and decision-making.

\section{The City as a Complex Urban Form}

Sustainable urbanism has been defined by Farr (2008) as 'walkable and transitserved urbanism integrated with high performance buildings and high-performance infrastructure'. Approaches seeking to develop sustainable urbanism practices combine urban growth and environmental protection, and include three fundamental dimensions: spatial development, socio-economic development and environmental-ecologic values (Albayrak \& Eryilmaz, 2017). Spatial development focuses on the urban form and addresses urban development concerns, mostly linked to the urban sprawling-compact development dilemma. The discussion around urban form and its relationship with sustainability has been mainly framed by a duality between the compact and disperse urban form. The study of the link between, urban form, density and sustainability presents contributions from theoretical and practical works which address density and sustainability at various levels, from city planning and urban design to public space and architectural design. According to Elkin, Hillman, and McLaren (1991), sustainable city 'must be of a form and scale appropriate to walking, cycling and efficient public transport, and with the compactness that encourages social interaction'. This definition refers to the European medieval cites. On the other hand, Jenks, Burton, and Williams (1996) highlighted that, the compact city is not necessary as compact and sharp-edges as the medieval city. Above all, the debate on sustainable compact city model is still on going in scientific community and numerous recent researches have been conducted, for instance, Joo Hwa P. Bay and Lehmann (2017).

It becomes clear that there are several views as to what a compact city is, that the compact city is not necessarily a homogeneous phenomenon. A main difference of view seems to be whether the sustainable city form should be monocentric or polycentric. Jabareen (2006) illustrates some advantages of the polycentric model: efficient for more sustainable modes of transportation, promote diversity, social cohesion and cultural development as well as a preservation of land from country-side and a breakdown of the mono-functionality. On an other hand, the monocentric model as defined by Frey (1999) as a 'compact form core to edge, with large concentrated centres' can help to, increase in alternative modes of transport (pedestrian streets, bicycles...), save land- 
use, conservation of countryside surrounding the cities, optimize and save both cost and size of the infrastructure of urbanization and reduce distance to activities increasing functional mix of land. However, such model of development is remarkable only at relatively small city in order to promote good access to facilities.

It seems that there isn't a common agreement on what is the "ideal" formal concept of sustainable urban form.

In the context of the development of urban sustainable perspectives, various authors have pointed out to the importance of understanding the urban form as a key element of urban sustainability. Porta (2001) for instance, examines the relationship between urban form and urban (social) sustainability by looking at how urban form affects the living behavior of local inhabitants in their utilization of public spaces, and in their social interaction. Jabareen (2006) has identified and assess four sustainable urban form concepts, and concluded "the ideal sustainable urban form according to the design concepts (...) is that in which high density and adequate diversity, compact with mixed land-uses and its design is based on sustainable transport, greening, and passive solar energy". For his part, Kärrholm (2008) has pointed out the importance of a careful investigation of the spatial scale and claims for a deeper morphological understanding of sustainable urban form rather than listening the ideal models. Moreover, the use of indicators to assess urban form is on the increase. Cities like Paris, London, Amsterdam or Brussels, for instance, have established a dashboard of indicators for sustainable planning.

Despite this attention, the concept and the role of urban shape have not been well established in the debate of sustainability development. While the three main elements of sustainable urban form have been examined - that is (1) the formal concepts, (2) the design criteria, (3) the scale of intervention - the impact of the urban form on urban sustainability remains elusive. This might be due to methodological difficulties linked to defining the most desirable form for a sustainable city and to measure the city's approach to urban sustainability.

Figure 1: Aspects of research in sustainable urban form

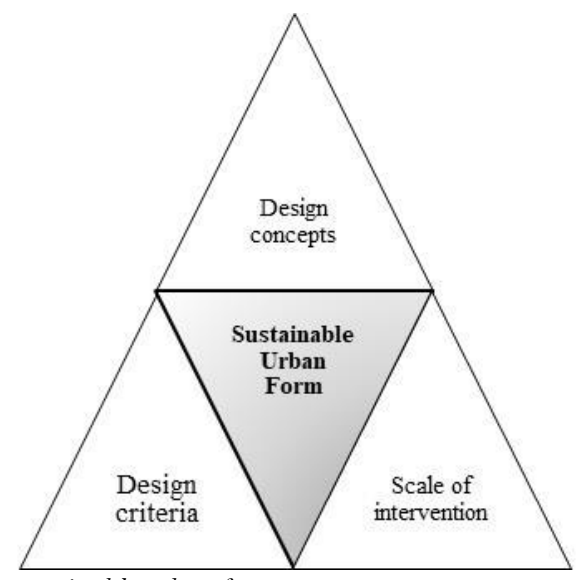

\section{Understanding Urban Form}


The difficulties of analysing the urban form lies, in the polysemy of the concept as well as the multidisciplinary aspects of this field of study: no agreement on the vocabulary, nor on the definition of the object analysis exist in urban form analyses. As noted by Merlin and Choay (2015), the term urban morphology is used in different senses, depending on whether it refers to an object of knowledge, urban form or the means that enable knowledge.

The second difficulty is related to the growth and changes of cities. Indeed, the recognizable opposition that existed in medieval towns with walls between inside vs outside, has been replaced by the dichotomy centre vs periphery in industrial cities. Human behaviour, needs, and technological development have been completely transformed, and so the humanized urban landscape described by Lynch (1964) has become endangered. Urban form, in this sense, represents a particular conception of a city in a period of time. The historical path of designing the whole city that has been lost during the modernist period needs to be taken into account in the future study of the urban form.

The interest in urban morphological analysis lies, first, in the enhancement of the relationships between different levels of organization of the urban fabric, second, in the identification of conflicts or convergence of relations established between street forms, buildings and plots.

The main components of urban form have been highlighted by Borie and Denieul (1984) (1) the path system is the connecting system of the country, which is the structural axis, (2) the plot system, which is the system partition of the territory into land unit, the plot fragments the territory, (3) the build system, which is all the masses of the urban build form, with their function or their size, and to finish, (4) the open space system, or the void, which is all un-built parts of the urban form - public or private. Thus, it seems that the form of the city is established in the relation between the distribution mode (outdoors space) and the occupancy mode (built space), which existing in a given area. Overall, these are the elements which have to be analyzed (i) by themselves, (ii) between themselves and (iii) in their relationship with other urban elements (Figure 2). 


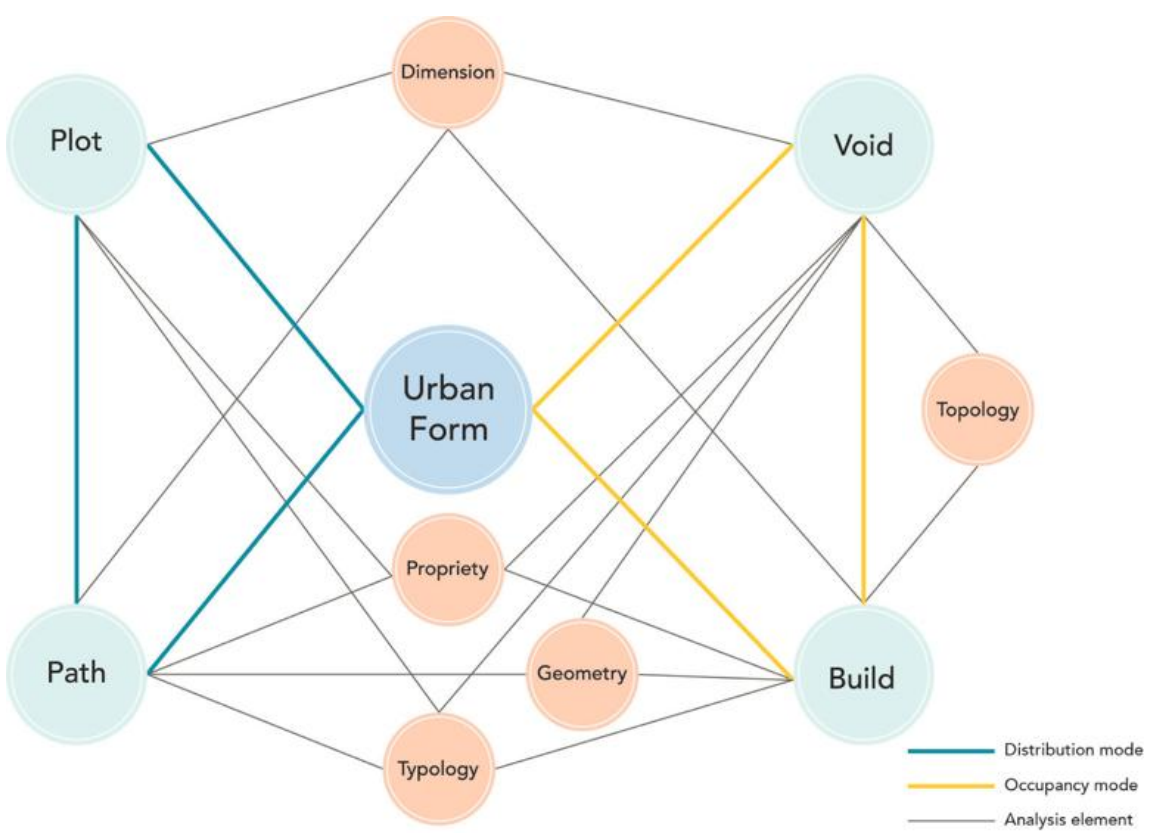

Figure 2: Urban form elements and systems

In brief, our understanding of urban form is that is an artefact, related to the aggregation of different elements - from void to build and from plot to path - in a define landscape which needs to be designed with a time process in order to form an urban tissue.

\section{Methodologies of Analysis Urban Form}

Different schools of thought have fueled the ongoing debate on the analysis of urban morphology and the study of urban form. Four schools can be identified: (1) the Anglo-German school (Conzen, 1962), (2) the French school (Philippe Panerai, Jean Castex, \& Depaule, 1977), (3) the Italian school (Muratori, 1960) and (4) the Space Syntax approach (Hillier, 1996) - after the 60s. While the first three have focused on the urban form in a descriptive and explanatory manner, Space Syntax approach has been concerned with how urban form is studied. They differentiate one another according to a) their historical approach to the analysis of the urban form; b) the examination of the type and morphology of the city and c) the analysis of the space and configuration of the city. Approaches looking at city's - morphology and configuration have origins in the fields of urbanism and architecture, while the historical and spatial analytical approaches have come out of the field of geography (Figure 3). 


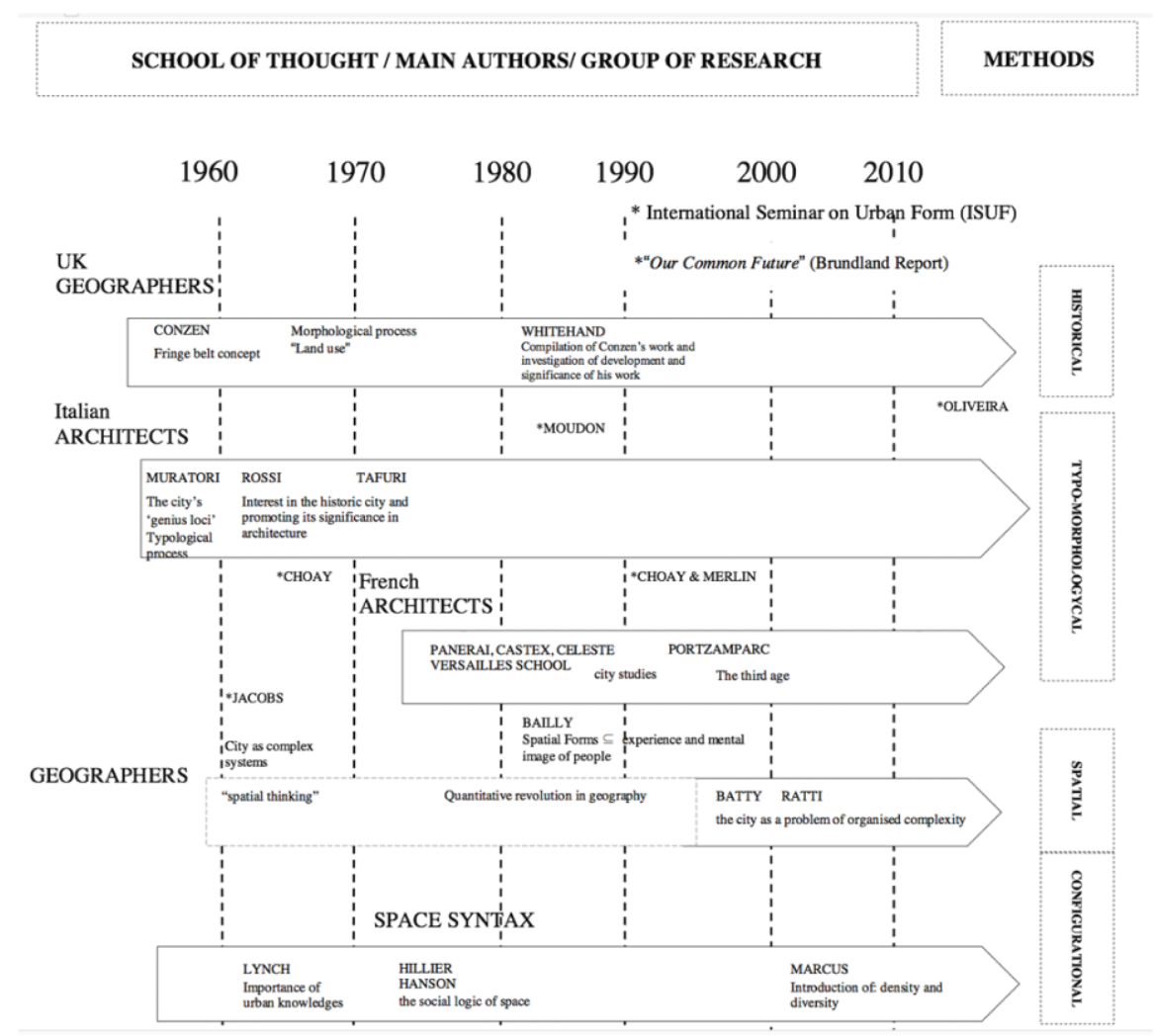

Figure 3: Picture of the keys references on urban form and urban morphology analysis

For historical approaches, the study of urban form across time is the main tool for understanding the shape of the city. This approach is based on the hypothesis that a city is a repository of history and material. Town plans are considered as a main source for analysis.

The historical approach examines two main objects in parallel:

1. Urban form is man-made and constructed overtime,

2. Second, is a focus on the ideal formation and structuration of its urban artefact.

The Italian school of thought (Muratorian School) rose during the 60s in reaction against modernist architecture and in rejection of history. The urban form it seen as the form of the urban fabric. The architects of the Muratorian School developed the typo-morphology approaches, which combine the study of urban morphology and study of architectural typology, at the junction of the two disciplines of architecture and urbanism. The typo-morphology method intends to upgrade the existing urban fabric and rejects the modern urbanism. Scholars ascribed to this approach think that the history of the city is embodied in the shape of the building in the street and in the plot, unlike modernists, who make abstractions on the history of a place.

In this context, the objective of this school of thought is to create a "storia operante" (active history) (Muratori, 1960). This "active history" should be able to guide the choices of the present, throughout including for intense the dematerialization of urban tissue types. In this perspective, "every built object is seen as the individualization of an 
historical process of specialization of forms" - where past, present and future are linked in an historical continuity - and belongs to a built type (Muratorian School, 1960).

The typo-morphology analysis mainly focuses on:

1. Making a critical assessment of the urban fabric's shape

2. Identifying structural concept link to the cultural identity of places and to the built heritage

3. To define measures to control the transformation of the built environment and to provide guidelines for supervising urban projects.

The use of typo-morphology methodology in the understanding of urban areas has a long research tradition (Moudon, 1997). However, the reach of this method into urban design practice has been limited (Hall, 2008) due mainly to: the difficulty of typological classification, the structure of the complex urban form, and the fact that more work is required on recent city forms (Grahame Shane, 2011). Moreover, various authors agree that there is a need to integrate different morphological approaches to obtain a more complete and complex set of urban environmental attributes (P. Conzen, 2010).

The quantitative revolution in geography (beginning of the 60s) and the development of Open Geographic Information System (GIS) and open data has enabled an increasing utilization of spatial analysis in planning tasks (Weber, Tammi, Anderson, \& Wang, 2016). Cellular Automata (CA), Agent Based Models (ABM) and fractals studies have provided complementary information to develop spatial analysis

Network analysis and analysis of any spatially defined objects are in the core of spatial analytical studies. Spatial approach can be portrayed as the scientific analysis of data (Thill, 2018). While the primary protagonists of this method were geographers (M. Dacey, B. Berry and others), they positioned their research at the boundaries of multiple disciplines which enable cross-relations and adoption of the spatial analytical approach by other disciplines (urbanism, architects, economics, ecologist...). In urban planning, the spatial analytical approach intends to pass over the difficulties in describing the urban environment and seeks to the representation of the city as "a geometry of order on many scales, a geometry of organized complexities" (Batty \& Longley, 1994). Spatial analysis methods allow to model spatial data, processes, and relationships in more nuanced, realistic ways than core GIS methods. Compare to the two-previous form of urban form analysis, the spatial analytical approach is more heterogeneous. Seeking to understand the spatial structure and dynamics of cities, Batty used a range of methods in his work enclosed in the book 'Cities and complexity' (Batty, 2007). According to Kropf (2009), Michael Batty's work and Centre for Advanced Spatial Analysis' work at University College London are the best to characterize the spatial analytical approach. They approach the city as a problem of organized complexity. Batty suggests that to understand cities "we must view them not simply as places in space but as systems of networks and flows”(Batty, 2013).

For their part, starting from the "syntactic" analysis of Provençal and English hamlets, Hillier and Hanson (1984) focused on the street system, using spatial accessibility as a key concept, in line with the Space Syntax school. The relationships between space and movement are two fundamental aspects of this approach. In doing so, they developed a new definition of the study object of the urban space with focus on 
the networks, structure of space and the social logic inherent in its representation. This focus on space emphasized the boundaries between the emerging Space Syntax and other approaches. They believed on the importance of studying the relationships between space, building and urban area instead of considering space on its own or simply as its defining surfaces.

\section{Discussion and Conclusion}

Urban form and its study are always dependent on the researcher and their background. From the research on literature review above, urban morphology analysis provides a comprehensive spatial context by first identifying the drivers of development and second situating spatial trends in history. Considering architectural and geographical approaches to the study of urban form, the morphological analysis requires; the classification of urban tissue by kinds, period of development and hierarchy of scales, in order to understand the production and transformation process of urban form, and to guide quality design practice. Following these three levels of organization, this research combined spatial and analytical tools to offer an integrated conceptual framework for studying the sustainable urban form (Figure 4).

First of all, the following three principles of our understanding of the urban form analysis have been highlighted and represented as analytical tool in our conceptual framework:

1. Urban form is defined by four primary complementary systems: street network/ path $(\mathrm{Pa})$, plot $(\mathrm{P})$, built patterns (B) and open spaces/ void (V) (cf. figure 2); the Type,

2. Urban form can only be understood historically since urban form evolves constantly in response to social, environmental, economic and technological developments (Williams, 2014); the Time

3. Urban form can be viewed from various geographical scales (Tsai, 2005); the Space

Secondly, the urban form needs to be understood with its spatial formation, architectural and environmental qualities of its forms in the context of sustainable urban development. Therefore, the primary elements of the urban tissue $-\mathrm{Pa}, \mathrm{P}, \mathrm{B}$ and $\mathrm{V}$-, are no longer as simple as such. Regarding the structure of the complex contemporary urban fabric, there is a need to fine-tune their understanding - as analytical tool - according to their:

1. Formal concepts,

2. The design criteria, and

3. The scale of intervention.

Understanding the range of issues across sustainability goals in the design process, is needed in order to address them at any given scale and to understand how urban design decisions will affect outcomes at the larger and/or smaller scale. Thus, the investigation of spatial scale as one vital aspect of sustainable urban form development have been addressed mainly throughout the scale of the city (e.g. the compact city model) or the neighborhood level (Kärrholm, 2008). However, in discussions link with polycentric vs monocentric model, for instance, research are focused at the regional scale (Okabe, 2005) where policy makers are deeply involved. It is then clear that some design concepts are more appropriate at certain scales than others. 
Thirdly, cutting across the debate on sustainable urban form, there are a number of key concepts, which have been reported in the section above - for instance, the notion of compactness, sustainable transport, density, mixed land uses, among others- which need to be taken into account in the sustainable urban form analysis. These concepts represent the grid of spatial analysis in our conceptual framework.

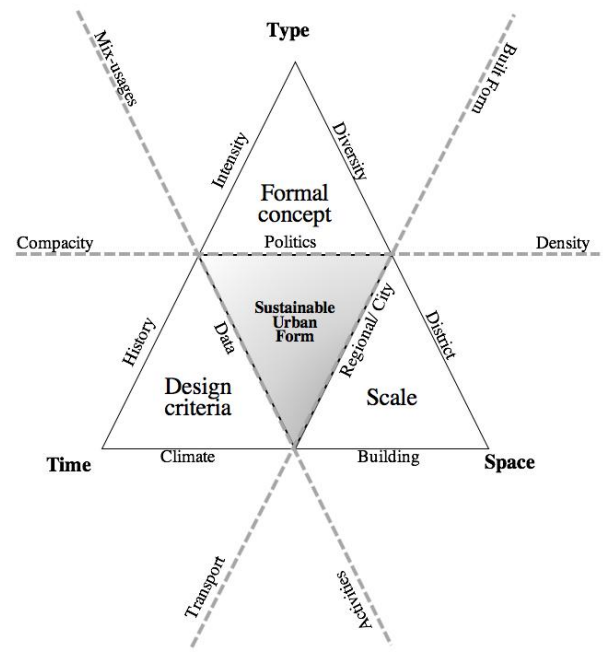

Figure 4: Conceptual framework to build an sustainable urban form

By studying the concept of urban form trough first, the four schools of thought and then replace it in the actual debate of sustainable urbanism we were able to synthetize in one conceptual framework the key design planning strategies, the elements of analysis needed and the hot point to study the urban form in its complexity.

Today, urban design practice requires a strong foundation with both physical and spatial responsibilities to guide future developments. In this sense, the research has proposed a new methodological framework, which could serve this purpose. This framework offers a way to monitor sustainable urban form. The theoretical background behind the framework is founded on a detailed review of the urban form literature and the typo-morphological approach in order to provide a bridge between them.

In doing so, we try to contribute to a better conceptualization of the terms "urban form" and "urban morphology", - which are often used interchangeably since there is no clear definition of their meaning- in the context of sustainable urban development. By breaking down the concept of urban form to its constituent elements, we are able to establish the relationship between urban form and urban system and urban structure.

Overall, we argue that a better understanding of these different forms and factors is needed in order to help with the future city development. Thus, urban form is not considered to be simply a set of data, but a subject of inquiry that depends on an assumed initial definition and conceptualization (Lévy, 2005). 
The research can also be extended regarding the availability and the cost of land and the socio-economic profile of the residents and how these are reflected in the development of sustainable urban form.

\section{References}

Albayrak, A. N., \& Eryilmaz, Y. (2017). Urban Growth in Sustainability Perspective. Int'l Journal of Advances in Agricultural \& Environmental Engg. (IJ A AEE), 4(1).

Batty, M. (2007). Cities and complexity : understanding cities with cellular automata, agent-based models, and fractals (1st MIT Press paperback ed.). Cambridge, Mass. ; London: MIT.

Batty, M. (2013). The New Science of Cities: The MIT Press.

Batty, M., \& Longley, P. (1994). Fractal Cities: A Geometry of Form and Function.

Borie, A., \& Denieul, F. (1984). Méthode d'analyse morphologique des tissus urbains tradiotionnels. Retrieved from http://unesdoc.unesco.org/images/0006/000623/062310fb.pdf

Elkin, T., Hillman, M., \& McLaren, D. (1991). Reviving the city : towards sustainable urban development

Frey, H. (1999). Designing the city : towards a more sustainable urban form. London; New York: E \& FN Spon.

Grahame Shane, D. (2011). Transcending Type: Designing for Urban Complexity. Architectural Design, 81, 128-287. doi:10.1002/ad.1197

Hall, T. (2008). Bridging the gap: Applying urban morphology to successful planning practice. Urban Morphology, 12, 54-57.

Hillier, B., \& Hanson, J. (1984). The social logic of space. Cambridge Cambridgeshire ; New York: Cambridge University Press.

Jabareen, Y. R. (2006). Sustainable Urban Forms : Their Typologies, Models, and Concepts. Journal of Planning Education and Research 26:38-52 DOI: 10.1177/0739456X05285119 (c) 2006 Association of Collegiate Schools of Planning.

Jenks, M., Burton, E., \& Williams, K. (1996). The Compact City: A Sustainable Urban Form?

Joo Hwa P. Bay, \& Lehmann, S. (2017). Growing Compact: Urban Form, Density and Sustainability: Routledge.

Kärrholm, M. (2008). Setting the Scale of Sustainable Urban Form - Some scale-related problems discussed in the context of a Swedish urban landscape. Paper presented at the Architectural inquiries, Goteborg.

Kropf, K. (2009). Aspects of urban form. Urban Morphology, 13(2), 105-120.

Lévy, A. (2005). Formes urbaines et significations: revisiter la morphologie urbaine. Espaces et Sociétés, pp2548.

Lynch, K. (1964). The image of the city (1st M.I.T. Press pbk. ed.). Cambridge, Mass.: M.I.T. Press.

Merlin, P., \& Choay, F. (2015). Dictionnaire de l'urbanisme et de l'aménagement.

Moudon, A. V. (1997). Urban morphology as an emerging interdisciplinary field. Urban Morphology, 1, 3-10.

Muratori, S. (1960). Studi per una operante storia urbana di Venezia. Roma: Instituto poligrafico dello Stato.

Okabe, A. (2005). Towards the Spatial Sustainability of City-Regions: A Comparative Study of Tokyo and Ranstad. In M. a. D. Jenks, N., (Ed.), Future Forms and Design for Sustainable Cities (pp. 55-72). Great Britain: Elsevier.

P. Conzen, M. (2010). The elusive common denominator in understanding urban form. Urban Morphology, 14, 55-58.

Thill, J.-C. (2018). Innovations in GIS\&T, Spatial Analysis, and Location Modeling. In J.-C. Thill (Ed.), Spatial Analysis and Location Modeling in Urban and Regional Systems (pp. 1-6). Berlin, Heidelberg: Springer Berlin Heidelberg.

Tsai, Y.-H. (2005). Quantifying Urban Form : Compactness versus 'Sprawl'. Urban Studies, vol. 42, $141-161$.

Weber, R., Tammi, I., Anderson, T., \& Wang, S. (2016). A Spatial Analysis of City-Regions: Urban Form \& Service Accessibility. Nordregio, Working Paper 2016:2.

Williams, K. (2014). Urban form and infrastructure: a morphological review. Retrieved from 